\title{
COPING WITH COVID-19: A NEW ONLINE EDUCATION MODEL
}

\author{
Mr. Tanmoy Sen Gupta
}

\begin{abstract}
After a long lockdown period, one thing that we as students had to face is that we had to move away from the traditional classroom programs and go for the online interaction and learning by our respected teachers. As far as the COVID-19 like situation is concerned, online education is the only way to cope up. And associatively the examination systems had been affected to a huge extent, and it had become the weakest part of the full learning process. But as far as the present e-learning system is concerned it can easily be stated that the views of the people are that the e-learning is not an effective way, and it does not hold any value in the career other than getting a promotion or an additional degree in papers only without a thorough knowledge and practical exposure based on the course.

In this paper we will discuss about a new education model which can reestablish the education base for the students who had kept themselves far away from daily attentive learning. The new model needs to be implemented with some new effective techniques to enforce learner to get evaluated based on their daily attentiveness and understanding on the topics along with some practical implementation of the knowledge. And in a situation to cope COVID-19 this model will stand ideal for learner to continue the learning process without visiting the Schools, Colleges and Universities.
\end{abstract}

KEYWORDS: COVID-19, e-learning, new model, value education, online education, Online Learning, Online Platforms, easy \& detailed evaluation.

\section{INTRODUCTION}

In the view of the COVID-19 situation, one important aspect which had emerged out is the elearning system. But as far the approach of the online education is concerned it is easily derivable that the students does not feel interested in the e-learning programs as they do in case of class room program. Moreover, there are various online evaluation systems, but none of them are effective enough and encourage students to go for unfair means.

So, there is a requirement of an advanced, effective, trustable model to be implemented to deliver the knowledge to the students in such a way that the students will learn effectively throughout the year rather than short learning of few weeks before exam, just to qualify the examination. And with the advancement of the technology an easy and fast evaluation technique could be implemented, which can also be used for counselling of the students. 


\section{DISCURSION}

With an objective to remodel the online education system few vital processes that must be associated with the traditional video calling classes, which will not only impart knowledge efficiently but also will build confidence among the public about the efficiency. The things which are taken into consideration in this model are:

- Focus on each and every student in the class, what ever may be the class strength.

- Detailed, dynamic, continuous, and speedy evaluation. (i.e. any time updated report availability)

- Interactive platform without interruption in class and,

- Especially fruitful outcome in terms of knowledge gained by the students.

The model is divided into two parts namely:

- Interactive interface,

- Evaluation process.

\section{Interactive interface}

This part can be described as below:

- Firstly, the framework of the website interface will be similar to any online group video conference calling with the following features:

(1) The host (Teacher) will have full control to allow any one to present, turn on/off video, audio.

(2) The host video/presentation will be pinned in everyone screen.

- Secondly, the vital thing that must be incorporated is:

(1) A section will be there along with the presentation section in the same screen which will show the questions asked by the teacher with four multiple choice answers.

(2) Each time the teacher clicks the "GO" button on the specific questions previously inputted by the teacher in the block of the teacher's screen, the pop up will appear in the student's screen.

(3) The popup will be visible on the student's screen until they clicks "GO" button or the teacher gives the second question.

(4) Now if the students click the "GO" button, the question will be displayed and a 45 seconds timer will allow the students to answer and submit, otherwise it will be submitted as blank. Once submitted the answer, it cannot be changed.

(5) If the students do not click the "GO" button within the second question arrives then it will be submitted as unanswered.

- Now as stated earlier, that teachers had to insert the questions and multiple-choice answers along with its actual answer, to be asked in the session before the session starts, which will be saved to database.

- All response from students will be saved to database, and will be evaluated automatically.

\section{$\underline{\text { Evaluation process }}$}

This part is divided into three parts: 
- Formative evaluation

- Summative evaluation

- Project evaluation

\section{Formative evaluation}

The formative evaluation will be based on the continuous and daily evaluative process. It will contain a detailed analysis of each student. Things that is incorporated in this process are listed below:

- The multiple-choice questions' answers which are saved in the database will be evaluated using programming language, automatically whenever teacher or students wants.

- It will be updated on daily basis after each class session finishes.

- This will lead the teacher to understand the attentiveness of the students and understanding of the subjects by the students on each class basis and overall basis and would help teachers to focus on the weaker part of the students and can take actions accordingly.

- On the other hand, the students will be able to point out the gap in their knowledge and can improve in it accordingly. And students will be able to download the questions and answers asked during the session.

- On addition to all the above points, this will write-off the requirement of the mandatory attendance criteria, as the student's absence and inattentiveness will cause them to lose marks.

- Moreover, the 45 seconds time for answering multiple choice questions will not let the students to for any unfair means to get marks.

\section{Summative evaluation}

The summative evaluation will take place at the end of each semester/year. Things that is incorporated in this process are listed below:

- Questions will be displayed on the screen and type area will be there along with an upload section will be there to upload answers and students will have to click submit to go to next question. Students can use the text box or use the upload section to give answers, whichever is comfortable for the students.

- A timer must be there to allow the students to submit the answers and as the timer stops, the answers will be automatically submitted and the window will close.

- Type of questions can be as specified by the universities.

\section{Project evaluation}

Till now we were talking about the knowledge part, but one most important aspect to evaluate a student is to check the student's ability to utilize the knowledge in real-life practical problem, and here comes the question of project.

Each student needs to be given a real-life project based on their syllabus covered in the particular semester/year and must be asked to give a presentation of the solution to the given project problem. This will not only check the student's ability but also will build confidence among the students to handle real life projects and build up communication skills too. 


\section{Total evaluation}

Total evaluation is the adding up of the formative evaluation, summative evaluation and project, keeping in note of the following points:

- The marks obtained must be added up in the 35:45:20 ratio. i.e. giving nearly equal priority to both formative evaluation and summative evaluation and eventually give priority to real-life problem solving.

- In detailed, we can say that the total marks obtained in formative evaluation and summative evaluation must converted to equivalent of total marks of 35 and 45 marks respectively.

- After conversion, all three must be added up to get the total marks obtained.

- Giving equal priority to the formative evaluation will draw attention of the students to attend classes seriously and will also help them to gets good marks easily by just attending the class attentively. And this will also help the students to get attentive in class, which was not familiar in case of classroom mode also. As it could be easily noted that in classroom mode few students don't pay attention, but remain in the class just for attendance.

- The marks obtained is fair enough to judge the student's ability cum knowledge, rather than the traditional way to focus on students memorizing skill.

\section{CONCLUSION}

The above-mentioned model has taken into consideration the facts of the students approach to online education system, mindset of people on ineffectiveness of online education system, and last but not the least, knowledge gathered by the students' through the education provided. Moreover, a detailed analysis of the evaluation will help both students and teachers to build up the weaker part of the students' understanding in a better way. And this will also help teachers to get more time to think on the subjects rather than to check copies of weakly/monthly test.

This model is made by keeping in mind about the students above primary level. As student of primary level may not be accustomed with the interface easily, but can be incorporated if being assisted by their guardian.

This model will not only build knowledge base of the students by enforcing them to pay attention to the class, but also will check student's ability and build trust of the corporates and peoples on the knowledge of the pass-outs of each batch. And finally, this model can prove itself efficient in a similar situation like COVID-19.

\section{FUTURE SCOPE}

The above-mentioned model has a huge scope in the future, not restricted to:

- Applicability of the model in distance education framework to make it effective and increase its value.

- The same model can also be implemented for primary level students with some modifications and with the guidance of their guardian.

- And with the evolution of artificial intelligence this model had a huge future scope of improvement like counselling of students, respective students' interest as a whole to guide them to follow the right path to have a bright future. 


\section{REFERENCES}

- Deepankar Vishwas Kotwal, Shubham Rajendra Bhadke, Aishwarya Sanjay Gunjal, Puspendu Biswas; "ONLINE EXAMINATION SYSTEM"; International Research Journal of Engineering and Technology (IRJET); Volume: 03, Issue: 01; Jan-2016; Page No. 115-117.

- Rahul Prakash Tiwari, Rahul Nishad, Priyansh Goel, Kaushal Kishor; "Online Examination System"; International Journal of Creative Research Thoughts (IJCRT); Volume 6, Issue 2; April 2018; Page No. 630-633.

- Gufranul Karim, Shaheena Ghazala, Md.Afroj, Shaik Maheboob; "A Novel Students Online Examination System"; International Journal for Modern Trends in Science and Technology; Volume: 03, Issue No: 02; February 2017; Page No. 1-4.

- Kartik Garg, Kushagra Rastogi, Raghvendra Pratap Singh; "A REVIEW PAPER ON ONLINE EXAMINATION PORTAL"; International Journal of Recent Scientific Research; Volume 10, Issue, 03(C); April, 2019; Page No. 31822-31824.

- Pravat Kumar Jena; "Impact of Covid-19 on higher education in India"; International Journal of Advanced Education and Research; Volume 5; Issue 3; 2020; Page No. 77 81

- $\quad$ Dr. Pravat Kumar Jena; “ONLINE LEARNING DURING LOCKDOWN PERIOD FOR COVID-19 IN INDIA"; INTERNATIONAL JOURNAL OF MULTIDISCIPLINARY EDUCATIONAL RESEARCH; Volume 9, Issue 5(8); May 2020; Page No. 82-92

\section{Mr. Tanmoy Sen Gupta}

(Student of Institute of Business Management, Jadavpur University)

P22, Pashupati Bhattacharya Road, Green Park, Behala, Kolkata

Email: tanmoys22@gmail.com, Mobile No.: 9748504819

ORCID ID: https://orcid.org/0000-0001-5649-2807 